\title{
Lucha por la libertad religiosa. Primeras misiones pentecostales en el Perú: las Asambleas de Dios en Áncash, 1919 a $1927^{1}$
}

\section{Carlos Guillermo Carcelén Reluz²}

Universidad Científica del Sur

\begin{abstract}
RESUMEN
El estudio del origen del pentecostalismo en el Perú es importante porque puede ayudar a entender las bases de la posterior difusión de su mensaje y el crecimiento del número de sus creyentes, que ahora pueden ser mejor identificados como evangélicos carismáticos o neopentecostales de clara influencia norteamericana ${ }^{3}$. Se hace necesario estudiar el tema en la medida en que los tiempos de cambio que vivimos plantean la importancia de los grupos considerados como minorías o culturas subalternas, como lo son las Iglesias evangélicas, pero también por la importancia y repercusión de su mensaje en la sociedad contemporánea y los cambios en las políticas republicanas relacionadas con la libertad de cultos desde el siglo XIX ${ }^{4}$.
\end{abstract}

\section{PALABRAS CLAVE}

Pentecostalismo, Asambleas de Dios, Áncash, Libertad religiosa.

1 Ponencia presentada en el I Coloquio de Estudios Históricos del Siglo XX, realizado del 6 al 9 de mayo de 2013.

2 Profesor de Historia de las Religiones en el Departamento de Historia de la Universidad Nacional Mayor de San Marcos. Profesor de Historia del Pensamiento Económico en la Facultad de Ingeniería Económica y de Negocios de la Universidad Científica del Sur. Máster y candidato a doctor en Historia de América Latina por la Universidad Pablo de Olavide de Sevilla.

3 Los predicadores norteamericanos de mayor influencia en el Perú son Jimmy Swaggart, Pat Robertson y Paul Yonggi Cho, así como los ministerios Club PTL y Club 700 (Amat 1997: 10).

4 Para referirnos a la sociedad contemporánea debemos considerar a la fe, la religión y los cultos dentro de una sociedad posindustrial, como un medio en el cual solo la tolerancia permitirá entender el desarrollo plural de la experiencia religiosa en nuestros días (Parker 1997). 


\section{ABSTRACT}

The study of the origin of Pentecostalism in Peru is important because it can help to understand which were the basis for subsequent dissemination of his message and the growing number of believers, which can now be better identified as evangelical charismatic or neo-Pentecostal American influence clear. Theme that is necessary to study the extent that we live in times of change raise the importance of minority groups or cultures considered subordinate, such as evangelical churches, but also by the importance and impact of your message in society contemporary and Republican policy changes related to freedom of religion since the nineteenth century.

\section{KEY WORDS}

Pentecostalism, Assemblies of God, Ancash, religious freedom.

\section{La coyuntura de la llegada de los protestantes}

Para llegar a una respuesta de nuestra interrogante central planteamos el desarrollo de un análisis histórico que aborda las circunstancias y acontecimientos mismos del establecimiento de las misiones en Áncash y también los que rodean al proceso general marcado por la coyuntura de la llegada y el establecimiento del protestantismo en el Perú.

Con respecto a esto último, el análisis del proceso de llegada y establecimiento del protestantismo en el Perú, debemos tener en claro que el pentecostalismo llegó más tarde que otras sectas importantes, como el anglicanismo, que se estableció en el país, pero como propia de los grupos de extranjeros, sobre todo anglosajones (Armas 1996: 112). También en la educación los protestantes tenían vigencia desde la creación de la Escuela Normal (hoy Universidad de la Cantuta) el 6 de julio de 1822, gracias a las gestiones de Diego Thomson (Gutiérrez 1996: 300).

Pero la primera experiencia en la cual el protestantismo entró en contacto con el pueblo peruano y se planteó como un credo proselitista es la protagonizada por el metodismo, que se estableció en el país en 1888 gracias a la llegada del italiano Francisco G. Penzotti (Armas 1993), que generó una respuesta violenta por parte de la jerarquía de la Iglesia católi$\mathrm{ca}^{5}$. Esto se presentó en los trabajos de predicación en Cocachacra, pueblo

5 Los detalles del proceso a Francisco Penzotti pueden leerse en Época, Revista de Historia Eclesiástica, año 2, nro. 3. 
cercano a Mollendo, cuando los misioneros fueron apedreados por los fieles católicos por instigación de los sacerdotes del lugar (Armas 1996: 104).

La violenta reacción se puede entender en esos años, ya que desde 1880 aproximadamente se suscitó una serie de polémicas en torno al problema de la «secularización de la vida cotidiana» a nivel de la tolerancia de cultos, la administración de los cementerios y el matrimonio civil ${ }^{6}$. Estas polémicas no solo se presentaron en el país, ya que, como respuesta al avance de la masonería, el Papa León XIII dio una nueva condena de la Iglesia en la encíclica Humanum Genus en 1886. En esta encíclica se ve a los masones, a los liberales y a los protestantes como aliados y enemigos de la Iglesia (Armas 1996: 104).

El conservadurismo y la represión lograron tener un importante apoyo a través de la formación en Arequipa de la Unión Católica, en 1886, institución que contó con el beneplácito y la simpatía del obispo de la ciudad, Juan Ambrosio Huerga (García Jordán 1989: 320). Este obispo sensibilizado por el arzobispo de Lima, Manuel Bandini, al respecto de la secularización de los cementerios, observó con mucha preocupación la tarea de Penzotti, ya que este último se trasladó a la ciudad de Arequipa a vender Biblias (Armas 1996: 104).

En febrero de 1890 el obispo Huerga, apoyado por la Unión Católica, denunció a Penzotti por contravenir el artículo IV de la Constitución, que fue promulgada el 1860. El denunciado fue arrestado, pero los reclamos de los representantes diplomáticos italianos ${ }^{7}$ dieron lugar a que el mismo presidente Cáceres enviara un telegrama a la ciudad de Arequipa ordenando la liberación inmediata de Penzotti y de sus dos seguidores: el uruguayo Arancel y el peruano Illescas (Armas 1996: 104). Estos colaboradores fueron denominados colportores, término usado para los vendedores de Biblias (Escobar 1997: 9).

Ya en libertad, Penzotti se trasladó al Callao, en donde continuó predicando en el templo creado en la calle Colón. El número de asistentes iba en aumento, por lo cual los sacerdotes del puerto iniciaron desde los púlpitos el ataque contra la «propaganda protestante». Esto dio lugar a que algunos feligreses, estimulados por sus párrocos, hostilizaran la casa donde se reunían los protestantes, tanto los misioneros como conversos. Los ataques en contra de Penzotti y los suyos fueron reforzados por el

6 Para una comprensión completa de este proceso de polémica y conflicto, tomamos como referencia el capítulo siete del importante estudio de García Jordán (1989: 221-258).

7 Armas Asín señala que la presión internacional era evidente y muy contundente en momentos en que el país vivía el problema de la discusión del Contrato Grace (1889). «Era importante la buena imagen del Perú» (Armas 1996: 112). 
arzobispo de Lima, Manuel Bandini, que publicó su Pastoral que don Manuel Bandini, arzobispo de Lima, dirige al pueblo del Callao con motivo de la predicación de un orador protestante, en la que se exigía a la feligresía porteña el rechazo a las ideas protestantes, instándoles a no asistir a sus prédicas, con la amenaza de censura y excomunión (Armas 1996: 105).

A pesar de la presión, Penzotti y los metodistas crearon la primera iglesia metodista del Perú en el puerto del Callao, en el mismo año de 1890. Esto motivó una mayor represión religiosa que se apoyó nuevamente en los principios constitucionales que fueron violados por Penzotti y sus seguidores como el artículo IV de la Constitución de 1860, que prohíbe la existencia de otros cultos religiosos. El denunciante esta vez fue uno de los sacerdotes del puerto del Callao, José Manuel Castro (Armas 1996: 106). La detención preventiva de Penzotti ocurrió el 25 de julio de 1890, y fue ordenada por el mismo presidente Cáceres, quien cedió a las presiones de los católicos limeños, pero la fuerza internacional ahora era encabezada por diplomáticos de Estados Unidos y el Reino Unido, en el país y en el exterior.

La libertad de Penzotti fue un objetivo político que se reflejó en la unidad de la presión diplomática, las gestiones de los liberales, los masones y la prensa progresista peruana e internacional. La unidad dio su fruto el 28 de marzo de 1891, cuando «la Corte Suprema puso en libertad a Penzotti, abriendo el camino para la llegada de las misiones protestantes» (Gutiérrez 1996: 302).

Luego de estos acontecimientos llegaron muchos misioneros protestantes, pero, a pesar del ejemplo del caso Penzotti, la represión religiosa no fue dejada de lado por el catolicismo peruano, que cada vez se sentía más agredido. La represión se manifestó nuevamente en Puno, en 1913, contra dos misioneros adventistas, los esposos Friedrich y Ana Stahl, que habían sido invitados al pueblo de Platería por su cacique Zuñiga Camacho, a fin de fundar escuelas y una clínica para ayudar a los indígenas de la zona (Gutiérrez 1996: 303). El mismo obispo de Puno, Valentín Ampuero, en compañía del gobernador, de dos jueces de paz de Chucuito y de una turba de más de 200 indígenas, se dirigieron al pueblo de Platería, destruyeron lo creado por los misioneros, y apresaron a los conversos y al propio cacique. Los detalles de la represión en el pueblo de Platería pueden ser leídos en Kessler 1987: 286-292.

Los hechos de platería dieron lugar a la formación de una corriente de opinión favorable a la tan discutida y polémica de la libertad de cultos, que fue acogida por importantes políticos e intelectuales de la época, como el educador José Antonio Encinas y los senadores por Puno Severino Bezada y Mariano H. Cornejo. La presión de los liberales, los masones y 
los protestantes logró imponerse a la posición de los católicos, al extremo que el mismo Congreso aceptó el debate de la libertad de cultos, a pesar de una forzada procesión del Señor de los Milagros, acompañada con una marcha de los católicos con rumbo al Congreso (Gutiérrez 1996: 303-305).

A pesar de las presiones, la decisión política estaba dada. El proyecto presentado por Severino Bezada fue aprobado en la Cámara de Senadores, en la sesión del 18 de setiembre, por todos los votos menos tres. El 3 de octubre fue aprobado en la Cámara de Diputados por todos los votos menos cuatro. El 11 de noviembre de 1915 se promulgó la Ley de Reforma del artículo IV de la Constitución, que desde ese momento permite la libertad de cultos (Stanger 1996: 81).

En estas circunstancias, ya en 1914 los misioneros protestantes como primera acción dividieron el territorio nacional para la evangelización y la fundación de sus iglesias. La ciudad de Lima fue considerada un lugar libre para cualquier misión. Al año siguiente nació la Alianza Evangélica del Perú, institución que se dedicó a la búsqueda de unidad y cooperación entre las diferentes misiones llegadas al Perú desde fines del siglo XIX (Gutiérrez 1997: 136) (ver cuadro 1).

CUADRO 1 | Sociedades y misiones protestantes inicio de actividades y lugar de procedencia

\begin{tabular}{|c|c|c|}
\hline Denominación & Año & Procedencia \\
\hline Iglesia Evangélica Metodista & 1888 & Estados Unidos \\
\hline Sociedad Bíblica Americana & 1888 & Estados Unidos \\
\hline Misiones Independientes & 1893 & Estados Unidos \\
\hline RBMU & 1893 & Inglaterra \\
\hline Unión Evangélica Sudamericana (EUSA) & 1903 & Inglaterra \\
\hline Iglesia de Santidad & 1903 & Estados Unidos \\
\hline Asambleas de Dios & 1908 & Estados Unidos \\
\hline Ejército de Salvación & 1910 & Inglaterra \\
\hline Iglesia del Nazareno & 1914 & Estados Unidos \\
\hline Sociedad Bíblica Británica & 1914 & Inglaterra \\
\hline Iglesia Libre de Escocia & 1916 & Escocia \\
\hline Iglesia Bautista & 1925 & Irlanda \\
\hline Fuente: Gutiérrez 1997: 135. & & \\
\hline
\end{tabular}




\section{Las primeras misiones de las Asambleas de Dios en el Perú}

Los miembros de las Asambleas de Dios tienen una larga tradición en nuestro país. Sus primeros misioneros, Howard C. Cragin y su esposa Clara, llegaron al Callao a mediados de abril de 1911, pero en Lima su mensaje pentecostal no encontró acogida entre los demás misioneros protestantes establecidos ya en el Perú desde fines del siglo XIX. Ante esta situación, los esposos Cragin se retiraron del Perú y se establecieron en la ciudad de Quito, Ecuador, en diciembre del mismo año de su llegada al Callao. Luego de una dura labor en el Ecuador, los Cragin se trasladaron a la ciudad de La Paz en 1914, para continuar con su prédica y labor social (Kessler 1987: 343).

En 1919 los matrimonios Hurlburt y Baker, misioneros de las Asambleas de Dios, por ese entonces la mayor Iglesia pentecostal de Estados Unidos, llegaron al Perú. Pero, al igual que a los Cragin, las cosas les fueron difíciles, ya que John Ritchie, director regional del Comité de la Cooperación en el Perú, después de observar el mapa que señalaba los territorios de las misiones en todo el país, les designó la zona de Áncash, donde no había ninguna misión evangélica (Jeter de Walker 1987: 13).

Los misioneros Barker y Hurlburt, tomando en cuenta lo dispuesto por John Ritchie, decidieron ir a la zona del callejón de Huaylas, en el centro de Áncash. Después de los preparativos, ellos y Esther, la hija de seis años de los Barker, se embarcaron en un vapor de carga rumbo al puerto de Chimbote. Aquí abordaron el tren que los llevó a la sierra del lugar de su misión. Durante el viaje los misioneros se enteraron de que el tren no llegaba al mismo pueblo de Huaylas y que, a pesar de su cercanía, no estaban preparados para cruzar la cordillera y llegar a su destino. Pero esta dificultad fue superada gracias a que en el tren conocieron a un comerciante del pueblo de Macate, quien los invitó a su pueblo para predicar. Este comerciante les proporcionó caballos para montar y burros para su equipaje, y así pudieron hacer el viaje de siete horas desde donde los dejó el tren hasta Macate, donde fueron hospedados por uno de los amigos del comerciante (Jeter de Walker 1987: 16-17). Es así como estos misioneros se establecieron en Áncash, J. R. Hurlburt y su esposa se instalaron en el pueblo de Macate, y Forrest G. Baker y su esposa Ethel, tomando como base al pueblo de Macate, penetraron en el callejón de Huaylas y se establecieron en el pueblo de Yungay al pie del Huascarán. Todo esto ocurrió en noviembre de 1919 (Jeter de Walker 1987: 16-17 y Kessler 1987: 344).

En 1920 llegaron a ayudar a los Barker tres misioneros más: Paul Cragin (hermano menor de Howard C. Cragin, que llegó al Perú en 1911) con su esposa, Eunice, y su suegra, Flora viuda de Hogan. Con este apoyo la misión creció, pero los sacerdotes católicos, poco capaces de aceptar la libertad 
religiosa ya establecida por ley, sintieron la amenaza e iniciaron una predica en contra de «los diablos protestantes». Además, amenazaron con la excomunión a cualquiera que los ayudase. A pesar del hostigamiento, los misioneros decidieron quedarse, lo cual enfureció a los curas, que incitaron a la gente a atacar a los protestantes y expulsarlos del pueblo. Los misioneros con los hijos de los Barker escaparon de su casa y se refugiaron donde uno de sus vecinos, pero al día siguiente el gobernador de la provincia les avisó que debían abandonar el pueblo 24 horas después. El aviso oficial explicaba claramente «que sus vidas no estaban seguras en Yungay y que las autoridades no contaban con suficientes fuerzas armadas para protegerlos contra un amotinamiento de la gente» (Jeter de Walker 1987: 29-30).

Con escolta policial los misioneros bajaron por el callejón de Huaylas y se trasladaron al pueblo de Caraz, donde la gente se presentó más receptiva, y se logró fundar una misión en esa ciudad. A pesar de ello, la misión duró poco tiempo, ya que los Barker decidieron retirarse al Callao (Jeter de Walker 1987: 30).

También en 1920 Paul Cragin fue a ayudar a los Hurlburt en la misión de Macate, pero en esos años, como muchos de los pueblos de la sierra de Áncash, los habitantes emigraron a la costa para trabajar en las grandes haciendas, y el pueblo y la misión quedaron sin almas. Con lo cual en 1922 se acabó la obra misional de Macate, ya que los Hurlburt se fueron al Callao y Paul Cragin se quedó en la región asignada a los pentecostales; regresó ese mismo año al pueblo de Caraz, pero también por poco tiempo, ya que en el año siguiente tuvo que abandonar el callejón de Huaylas. Con esto se abandonó la obra misional en Áncash, hasta la llegada de un nuevo contingente de misioneros en 1926 (Kessler 1987: 344-346).

\section{Los problemas de la actividad misional}

Los Hurlburt fundaron la primera iglesia de las Asambleas de Dios en el puerto del Callao en $1922^{\circ}$, y en ese mismo año los esposos Barker hicieron lo mismo en Huancayo, donde los metodistas habían estado establecidos durante muchos años (Kessler 1987: 344). En ambas ciudades se crearon iglesias pentecostales a pesar de los acuerdos de 1917, bajo la dirección de John Ritchie, entre las congregaciones evangélicas instaladas en el Perú. En estos acuerdos se asignaban regiones específicas para el establecimiento de las misiones de cada congregación o iglesia

8 Kessler 1987: 344. Con respecto a esta información, Marzal (1989: 293) toma la información de Huamán (1982) y señala que el fundador de la iglesia del Callao fue Forrest Barker, lo cual es errado. 
evangélica en el Perú. Como ya se mencionó, a los pentecostales se les asignó la región correspondiente al departamento de Áncash.

Esto provocó una serie de problemas con las congregaciones ya establecidas y los pentecostales, puesto que los primeros en establecerse en territorios asignados a otras congregaciones fueron ellos y, en particular, los de las Asambleas de Dios, lo cual desató una reacción en cadena que provocó la rivalidad que tanto ha empañado la imagen del movimiento evangélico en el Perú (Kessler 1987: 344-345).

La misión de Huancayo fue creada y organizada por los ya conocidos esposos Forrest y Ethel Barker, en medio de la oposición de los sacerdotes y la rivalidad de los metodistas. A pesar de ello, es la que más duró en esos años, gracias a la vitalidad de los Barker y al carácter más secular y urbano de la ciudad de Huancayo. Después de un tiempo, el misionero Raphael Lightner se unió a su tarea en los pueblos vecinos de la ciudad. En 1930 los misioneros esposos Richard y Minnie Williams llegaron para ayudar a la tarea misional en Huancayo y los pueblos y comunidades aledaños (Jeter de Walker 1987: 31).

Siguiendo a Marzal, se debe tomar en cuenta un acontecimiento de 1925, en la iglesia pentecostal del Callao, que no se menciona en las historias escritas por miembros de las Asambleas de Dios como Jeter de Walker o por evangélicos como Kessler (Marzal 1989: 293). Resulta que ese año, cuando era pastor de la iglesia del Callao el misionero Howard C. Cragin, la iglesia sufrió una división: la membresía más antigua se quedó con el templo y se incorporó al movimiento pentecostal Solo Jesús, mientras que la membresía más nueva constituyó una nueva iglesia llamada Luz Divina, que formó parte de las Asambleas de Dios (Huamán 1982: 49).

Parece que esta división es la que empujó a Howard C. Cragin a iniciar los preparativos para retomar las misiones en Áncash el año siguiente de 1926. La iglesia del Callao, según el mismo Kessler, estuvo a cargo de los esposos Hurlburt hasta 1929, año en que fueron sucedidos por un pastor peruano (Kessler 1987: 346-349).

Si tomamos en cuenta lo explicado por Huamán y resaltado por Marzal, con seguridad Kessler nos habla de la iglesia Luz Divina, que siguió siendo parte de las Asambleas de Dios. Más allá de las precisiones históricas, estamos de acuerdo con la lógica interpretativa de Marzal al señalar el aspecto simbólico de esta primera división:

Este cisma ocurrido en la primera iglesia pentecostal peruana es todo un símbolo de lo que sucede frecuentemente con las Asambleas de Dios y con otras denominaciones pentecostales. Como cada iglesia es autónoma y como los pastores y muchos de los miembros 
suelen tener la seguridad personal de que el Espíritu Santo los guía, no es extraño que los conflictos normales en cualquier grupo humano se resuelvan en cismas, que no afectan la doctrina ni la liturgia pentecostal, sino únicamente al liderazgo de determinados pastores o miembros. A pesar de eso, las Asambleas de Dios y las demás denominaciones pentecostales siguen creciendo, sobre todo entre los sectores más empobrecidos del país, y ya se vio cómo en la Gran Lima las Asambleas son la denominación más numerosa entre las evangélicas y pentecostales (Marzal 1989: 293).

\section{El regreso al callejón de Huaylas: las heridas de Huaraz}

Estamos seguros de que los problemas de liderazgo presentados en 1925 en la iglesia del Callao, y que dieron lugar al primer cisma en el pentecostalismo desde las Asambleas de Dios, fue la causa del reinicio de las actividades misionales en el callejón de Huaylas. Pero antes de retomar la tarea en Áncash, debemos observar que los esposos Cragin regresaron al Perú de Bolivia y se establecieron en el Callao, en donde, junto con los esposos Lief y Florence Erickson, continuaron la labor pastoral y durante ese año también buscaron un lugar para establecer una misión. Como resultado de esa búsqueda, hicieron un viaje exploratorio al departamento de Huancavelica, pero no encontraron las bases que satisficieran su labor misional. Y en medio de esta problemática búsqueda, el director de la Cooperación, John Ritchie, les sugirió dirigirse a la ciudad más grande del callejón de Huaylas: Huaraz. Esta información fue proporcionada por Walter Erickson y citada por Kessler (1987: 345).

Como parte de los preparativos, los nuevos misioneros fueron enviados al pueblo de Caraz, para tener unos días de orientación y aprendizaje del idioma quechua. Estos misioneros fueron los hermanos Erickson -Arthur, Lief y Walter-, Florence (la esposa de Lief), y las señoritas Olga Pitt y Ruth Couchman (Jeter de Walker 1987: 32).

Huaraz, como en los otros lugares en los que se establecieron anteriormente los misioneros pentecostales, presentaba el inconveniente de la oposición de los sacerdotes católicos, quienes predicaban en contra de los protestantes. De esta manera, la población miraba los esfuerzos misioneros con sospecha y hostilidad. Como señala Jeter de Walker: «EI progreso era lento». A pesar de la oposición, los Cragin (Howard y Clara) y los Erickson (Lief y Florence), decidieron celebrar su primer servicio bautismal, que era también el primero realizado por los evangélicos en toda la zona del callejón de Huaylas. Este servicio fue organizado el 27 de febrero de 1927 (Jeter de Walker 1987: 32).

La reacción de los sacerdotes contra los evangélicos fue por demás clara, debido a su condición de ser miembros de una Iglesia que se considera 
como la única representante de Dios en la Tierra. El hecho de la conversión para esos años supone, según Jeter de Walker, que:

el ser bautizado por los protestantes sería renunciar públicamente a la Iglesia católica apostólica y romana, la religión del Estado. Tremenda traición. La Constitución garantizaba la libertad religiosa, pero todo hijo leal de la Iglesia tenía la obligación de luchar contra todo lo que constituyera una amenaza a la supremacía de su religión. Además, si la gente llegara a creer que la salvación era don gratuito de Dios, como esos protestantes tan a menudo afirmaban, se afectarían los ingresos económicos de los sacerdotes (Jeter de Walker 1987: 32-33).

Parece que la autora no exageró en lo antes dicho, ya que uno de los sacerdotes aseguró a sus feligreses que si permitían a los evangélicos bautizar en el río Paria, la Virgen lo haría secar como castigo (Sumrall 1944: 63). Luego de esto, el mismo obispo de Huaraz, fray Domingo Vargas, incitó a sus feligreses - indígenas, principalmente - contra los misioneros y los creyentes dispuestos a convertirse (Kessler 1987: 346).

El día del culto, 27 de febrero, los misioneros y los nuevos creyentes decididos a convertirse, a pesar de las amenazas, cantaban sus himnos junto al río Paria, en las afueras de Huaraz. Y en el momento mismo en que Howard C. Cragin bajaba a las orillas del río con los candidatos al bautismo (Jeter de Walker 1987: 34), apareció una turba de 300 indígenas en estado de ebriedad, armados de piedras y palos, decididos a detener por la violencia la ceremonia. Kessler menciona estos acontecimientos resumiendo los informes publicados en medios de prensa pentecostal en Chile:

Howard Cragin fue gravemente herido y quedó tendido inconsciente en el suelo. Su esposa fue abatida y después arrastrada por los cabellos. Lief Erickson recibió el impacto de una piedra que le hundió el cráneo, causándole un daño permanente. La situación se hubiera vuelto peor de no haber sido por el heroísmo de los hermanos nacionales, que arrastraron a Cragin a un lugar seguro, y de la señora Erickson, quien levantó a su esposo y lo ayudó a escapar (Kessler 1987: 346).

En medio del ataque, alguien llamó a la Policía, que logró arrestar a los cabecillas, pero el obispo Vargas amenazó con incitar a sus feligreses indígenas contra la ciudad si no se liberaban a los encarcelados. Ante esta actitud, las autoridades los pusieron en libertad (Kessler 1987: 346-347).

La represión religiosa no se detuvo. En días posteriores otra turba intentó destruir el templo, pero no tuvo éxito gracias a la protección policial. Luego de estos ataques, los misioneros enviaron un telegrama al presidente de la República denunciando tal persecución anticonstitucional. La 
respuesta no se dejó esperar: «el presidente dio órdenes estrictas a las autoridades en Huaraz de evitar que se produjera otra vez tal oposición. Estas tomaron las medidas necesarias, y desde entonces los evangélicos pudieron seguir celebrando sus cultos sin persecución en esa zona» (Jeter de Walker 1987: 35).

Pese a esta mala experiencia, los misioneros esposos Cragin permanecieron en Huaraz durante toda su vida. Consolidaron su misión e iglesia, y trabajaron en la traducción de una parte de la Biblia al quechua. La labor de los esposos Cragin es descrita de la siguiente manera por Jeter de Walker:

Orientaban a nuevos misioneros en cuanto al idioma y a los métodos de evangelización. Howard estableció un sistema de circuitos para poder llevar el evangelio a todas las poblaciones en varias provincias. Correspondía con los convertidos y simpatizantes. Él y sus colegas los ayudaban a formar sus propias congregaciones (Jeter de Walker 1987: 35-36).

Con la llegada a Huaraz, en mayo de 1927, de Walter Erickson, y en julio de 1928, de Arthur Erickson, los hermanos de Lief (Kessler 1987: 347), las Asambleas de Dios tomaron la ciudad de Huaraz como la base y campo de acción principal de los pentecostales en el callejón de Huaylas (Hamilton 1962: 53).

\section{El crecimiento de las Asambleas de Dios}

Después de los acontecimientos de la ciudad de Huaraz de febrero de 1927, las Asambleas de Dios comenzaron a desarrollar las misiones e iglesias ya existentes en Callao, Huancayo, Caraz y Huaraz, y a establecer nuevas misiones e iglesias en Lima, Miraflores, Trujillo, Chiclayo, Arequipa, Puno, Cusco e lquitos. Todo esto en aproximadamente 20 años, como lo sostienen Jeter de Walker (1987) y Kessler (1987).

El crecimiento del pentecostalismo en el Perú fue y es más rápido que en otros países de América y en Europa. Esto puede entenderse, en parte, por el gran apoyo económico proveniente de Estados Unidos, como testimonia Juan Ritchie, quien fue el director regional del Comité de la Cooperación en el Perú en 1932, como fue investigado por Fonseca (1997), y a lo que se unió la rápida aceptación de su mensaje por los creyentes, quienes se unieron a la tarea misional.

Este crecimiento puede ser entendido porque se presenta como un «remedio a la anomía», es decir, al «desmoronamiento del sistema de la hacienda, éxodo rural hacia las ciudades, deserción institucional del clero católico», como glosa Motte el texto de Bernardo Guerrero. Además de 
esto, su crecimiento puede entenderse también porque el pentecostalismo se plantea como:

- El advenimiento de la emocionalidad, como factor de subversión democrática, en el culto y en la sociedad.

- El surgimiento de nuevos actores: los pobres (de bienes materiales y culturales), los jóvenes, la música, las mujeres. ¿Y quizá nuevos empresarios o nuevos políticos? (Motte 1996: 227).

Un caso peculiar para observar la fuerza de la prédica pentecostal en medios totalmente adversos, por ejemplo, es el que se presentó en la España franquista, donde las Iglesias protestantes crecieron a pesar del manifiesto apoyo político de la Iglesia católica a la dictadura y el poder que esta adquirió con nuevas congregaciones cada vez más dogmáticas. Los pentecostales en España presentaron un rápido crecimiento: eran unos 233 en 1955 y llegaron a ser más de 3.500 en 1960 (Ruperez 1970: 55-56).

En comparación con la España franquista, la oposición al pentecostalismo en el Perú después de los sucesos de Huaraz es casi nula — hay que tener en cuenta que desde 1915 existe libertad de cultos- y en cambio se configura una situación histórica propicia para su crecimiento. Wilfredo Kapsoli, quien recoge testimonios en los que se observa el empeoramiento en condiciones materiales y la ruptura con la tradición campesina andina, explica la situación como las causas de la desorientación que es revertida por el mensaje pentecostal, que se constituye así en forjador de una nueva identidad religiosa y ética en el nuevo medio urbano (Kapsoli 1994: 235-301).

Como un aporte comparativo podemos tomar el caso de la presencia pentecostal entre los aimaras del norte de Chile.

¿Cómo se presenta la secta? Para el que ingresa al pentecostalismo, la sociedad aimara es fuente de lo «diabólico». Todo lo que deviene de esta sociedad y de su tradición es asociado al «mal». La cosmovisión pentecostal expresa una dualidad que extrema en dos polos antagónicos la realidad, polos que están envueltos en una lucha definitiva. El bien contra el mal, espíritu versus materia, es la constante de su visión del mundo y de su discurso religioso. La vida es concebida en un «antes» y en un «después». [...] La conversión personal significa cortar los lazos con la tradición y revitalizar los lazos sociales y de la familia. La comunidad pentecostal se autopercibe como la representante de la sociedad del bien, la sabiduría y el cielo, y la sociedad andina encarna al mal, la ignorancia y el infierno, que hay que combatir (Van Kessel 1991: 65).

Este punto de vista que nos presenta al pentecostalismo en las zonas aimaras chilenas como una corriente modernista que ataca la tradición 
indígena (Guerrero 1984) es opuesto en lo referente al medio urbano, ya que en este medio la adopción de las prácticas pentecostales entre las poblaciones menos favorecidas por la economía urbana capitalista:

los marginados de las sociedades latinoamericanas crearon una especie de contrasociedad [al interior de sus respectivas iglesias o comunidades pentecostales], donde se reorganizaban las relaciones de solidaridad y se reencontraba la fuerza para vivir en un contexto nuevo (Bastian 1994: 247).

El punto de vista de Bastian (1994) se acerca al de Kapsoli (1994), ya que ambos centran su atención en los espacios urbanos, en los que observan los problemas de la integración cultural de los migrantes en un nuevo medio en muchos casos hostil al suyo.

A pesar de la diversidad de posturas que pueden explicar del desarrollo del pentecostalismo en el país, tenemos que aceptar lo que uno de sus líderes señala —-como un balance de su crecimiento y accionar-, respecto a los aportes concretos a nivel de su relación con sus creyentes:

Uno de los aportes concretos del sector pentecostal, comunidad cristiana compuesta mayoritariamente por pobres, ha sido la oferta de la sanidad divina. Frente al agudo problema de la salud y la imposibilidad de los humildes de acceder a los sistemas de seguridad social, la práctica del don de la sanidad ha sido una eficaz respuesta para aliviar los males físicos de muchas personas. Asimismo, el otro aporte significativo ha sido el reconocimiento social de los pobres, a quienes no solo les ha permitido hablar, sino ser activos constructores de lo que hoy es el pentecostalismo (Arboleda 1995: 77).

Este crecimiento que se aprecia en el pentecostalismo lleva consigo la marca de los problemas producidos por los constantes cismas, que son explicados por el carácter descentralizado de sus iglesias y el fuerte conflicto de liderazgo carismático, como lo sostiene Marzal (1989: 293).

Desde 1933, la Iglesia pentecostal Asambleas de Dios sufre un proceso de cismas y fraccionamientos, producto de los conflictos de liderazgo carismático entre los pastores. Esto da lugar a que en la actualidad ya no se hable de Iglesia pentecostal, sino de Iglesias pentecostales o de denominaciones pentecostales en el país. Entre las principales denominaciones pentecostales establecidas en la actualidad en nuestro país, podemos señalar a la Iglesia de Dios de la Profecía, las Asambleas de Dios, la Iglesia Misionera Emaús Pentecostal, la Iglesia Misionera Esmirna Pentecostés del Perú, el Movimiento Evangelístico Misionero, las Iglesias Independientes, entre otras (Marzal 1989: 286-310). 


\section{Palabras finales}

Como conclusión, podemos decir que, desde el establecimiento de las primeras misiones en la sierra de Áncash, el desarrollo del pentecostalismo en las poblaciones andinas significó y significa la construcción de nuevos vínculos sociales que rompen con las tradicionales estructuras de parentesco y con los referentes sociales consuetudinarios propios de las comunidades andinas. De esa manera, podemos decir que la prédica pentecostal en realidades como la nuestra se enmarca en el proyecto modernizador del capitalismo norteamericano, pero desde su versión más sublime y supuestamente desinteresada, que es la de una nueva evangelización.

Haciendo un paralelo, podemos decir que el caso de las misiones pentecostales en Áncash y, de manera general, el desarrollo del pentecostalismo latinoamericano presenta las siguientes características, que lo hacen peculiar en comparación con las otras sectas o denominaciones evangélicas, y con el mismo desarrollo de las misiones católicas contemporáneas, como son:

- El ser un «movimiento popular», en oposición a las tendencias cada vez más elitistas del catolicismo latinoamericano.

- Manifiesta un «sentido de identidad» a sus creyentes, en especial en las poblaciones marginales, puesto que les brinda una imagen de unidad y a su vez se consolida nuevos espacios sociales que se utilizan para mantener niveles mínimos de bienestar.

- Plantea la «sanidad» como forma de vida, algo que resulta importante en poblaciones «fundamentalmente urbanas» con niveles de alcoholismo, drogadicción y maltrato familiar altos.

- Es un movimiento «fundamentalista y antiintelectual», que se expresa en una lectora dogmática, pero siempre tamizada por el pastor. Esto último da lugar a una «variedad teológica» en su forma de explicar su propia religión, ya que podrían existir tantas versiones como pastores. Ello lo convierte en un movimiento muy «heterogéneo», en cuanto a las características de las tendencias y a sus luchas internas.

- Manifiesta duras críticas de los sectores cristianos que buscan explicar e interpretar las escrituras desde puntos de vista filosóficos, lo que lo convierte en una reacción «contra cualquier traza de racionalismo» en la religión y lo reduce a un «pietismo revivalista» opuesto a una revelación razonada.

- Se manifiesta en un «enorme crecimiento numérico» (Deiros y Mraida 1994: 67).

- Con todo ello se puede señalar que la capacidad transformadora del pentecostalismo peruano reside «en su apertura a nuevas prácticas sociales en momentos decisivos y definitorios de una sociedad en transición» (Campos 1994). 


\section{REFERENCIAS BIBLIOGRÁFICAS}

AMAT Y LEÓN PÉREZ, Oscar (1997). «lglesia y carismatismo». En Caminos, nro. 56.

ARBOLEDA PARIONA, Samuel (compilador) (1994). Iglesia y realidad social en el Perú. Lima: CEPS.

ARMAS ASÍN, Fernando (1993). Sobre las ilusiones y los desencantos. La lucha por la tolerancia de cultos en el Perú del siglo XIX. Tesis para optar el grado académico de licenciado. Lima: Pontificia Universidad Católica del Perú.

(1996). «Sobre protestantismo y radicalismo ultramontano: el affaire Penzotti en la polémica por la tolerancia de los cultos (1890)». En Tomás Gutiérrez. Protestantismo y política en América Latina y el Caribe. Lima: Cehila.

(1998). Liberales, protestantes y masones. Modernidad y tolerancia religiosa. Perú, siglo XIX. Lima y Cusco: Centro de Estudios Regionales Andinos Bartolomé de las Casas y Fondo Editorial de la Pontificia Universidad Católica del Perú.

BASTIAN, Jean-Pierre (1994). Protestantismo y modernidad latinoamericana. Historia de las minorías religiosas activas en América Latina. México D. F.: Fondo de Cultura Económica.

CAMPOS, Bernard (1994). «El pentecostalismo, en la fuerza del espíritu». Consultado el 7 de diciembre de 2011 de http://www.pctii.org/cyberj/ campos.html

DEIROS, Pablo A. y MRAIDA, Carlos (1994). Latinoamérica en llamas. Miami: Editorial Caribe.

ESCOBAR, Samuel (1996). «Libertad religiosa en el Perú. El proceso a Francisco Penzotti (1890-1891)». En Época, Revista de Historia Eclesiástica, año 2, nro. 3.

(1996). «Introducción al proceso de Francisco Penzotti».

En Época, Revista de Historia Eclesiástica, año 2, nro. 3.

FONSECA ARIZA, Juan A. (1997). «La Misiología de la Iglesia de Dios del Perú: una perspectiva histórica». Consultado el 7 de diciembre de 2011 de www.fratela.org/ponencias/ juan-fonseca.htm\#_ftnref4

GARCÍA JORDÁN, Pilar (1989). Iglesia y poder en el Perú contemporáneo, 1821-1919. Cusco: Centro de Estudios Regionales Andinos Bartolomé de las Casas.

GUERRERO JIMÉNEZ, Bernardo (1984). Movimiento pentecostal, corrientes modernistas y sociedad aymara. En Cuadernos de Investigación Social, nro. 8. 
(1994). A Dios rogando... Los pentecostales en la sociedad aymara del norte grande de Chile. Ámsterdam: Vrije Universiteit.

GUERRERO JIMÉNEZ, Bernardo y VAN KESSEL, Juan (1987). Sanidad y salvación en el altiplano chileno. Del yatiri al pastor. En Cuadernos de Investigación Social, nro. 21.

GUTIÉRREZ, Tomás (1996). Protestantismo y política en América Latina y el Caribe. Lima: Cehila.

(1996). «Los evangélicos. Un nuevo rostro en la política peruana de los 90 ». En Samuel Gutiérrez (compilador). Protestantismo y política en América Latina y el Caribe. Lima: Cehila.

(1997). Los evangélicos en Perú y América Latina: ensayos sobre su historia. Lima: Cehila y Archivo Histórico del Protestantismo Latinoamericano.

HAMILTON, Keith E. (1962). Church Growth in the High Andes. Indiana: Lucknow Publishing House.

HUAMÁN, Santiago A. (1982). La primera historia del movimiento pentecostal en el Perú. Lima: Imprenta El Gallo de Oro.

JETER DE WALKER, Luisa (1987). Oro peruano. Miami: Editorial Vida.

KAPSOLI, Wilfredo (1994). Guerreros de la oración. Las nuevas Iglesias en el Perú. Lima: Serec.

KESSLER, Juan B. A. (1987). Historia de la evangelización en el Perú. Lima: El Inca.

MARZAL, Manuel (1989). Los caminos religiosos de los inmigrantes en la Gran Lima. El caso de El Agustino. Lima: Fondo Editorial de la Pontificia Universidad Católica del Perú.

MEYER, Jean (1989). Historia de los cristianos en América Latina. Siglos XIX y $X X$. México D. F.: Editorial Vuelta.

MOTTE, Dominique (1996). «A propósito de A Dios rogando... Los pentecostales en la sociedad aymara del norte de Chile». En Revista Andina, año 14, nro. 1, vol. 27.

PARKER, Cristian (1997). Religión y posmodernidad. Lima: Proceso Kairos y CEPS.

RUPÉREZ, Javier (1970). Estado confesional y libertad religiosa. Madrid: Edicusa.

RITCHIE, Juan (1996 [1932]). «La Iglesia autóctona en el Perú». En Época, Revista de Historia Eclesiástica, año 2, nro. 2.

STANGER, Frank (1997 [1925]). «lglesia y Estado en el Perú independiente». En Época, Revista de Historia Eclesiástica, año 2, nro. 2. 
SUMRALL, Lester F. (1944). Through Blood and Fire in Latin America. Michigan: Grand Rapids.

VAN KESSEL, Juan (1991). «Los aymaras contemporáneos de Chile (18791990): su historia social». En Diálogo Andino, nro. 10.

Recibido: Noviembre de 2011. Aceptado: Enero de 2012. 